\author{
WAPD-TM-1123 \\ AEC Research and Development Report
}

\title{
Irradiation Induced \\ Primary Creep
}

C.C. Dollins

R.P. Tucker

Bettis Atomic Power Laboratory

Pittsburgh. Pennsylvania 15122

April 1974 


\section{DISCLAIMER}

This report was prepared as an account of work sponsored by an agency of the United States Government. Neither the United States Government nor any agency Thereof, nor any of their employees, makes any warranty, express or implied, or assumes any legal liability or responsibility for the accuracy, completeness, or usefulness of any information, apparatus, product, or process disclosed, or represents that its use would not infringe privately owned rights. Reference herein to any specific commercial product, process, or service by trade name, trademark, manufacturer, or otherwise does not necessarily constitute or imply its endorsement, recommendation, or favoring by the United States Government or any agency thereof. The views and opinions of authors expressed herein do not necessarily state or reflect those of the United States Government or any agency thereof. 


\section{DISCLAIMER}

Portions of this document may be illegible in electronic image products. Images are produced from the best available original document. 
C. C. Dollins

R. P. Tucker

April, 1974
This report was prepared as an account of work sponsored by the United States Government. Neither the United States nor the United States Atomic Energy Commission, nor any of their employees, nor any of their contractors, subcontractors, or their employees, makes any warranty, express or implied, or assumes any legal liability or responsibility for the accuracy, completeness or usefulness of any information, apparatus, product or process disclosed, or represents that its use

would not infringe privately owned rights.

Contract AT- (36-1)-GEN-14

\author{
Printed in the United States of America \\ Avallable from the \\ National Technical Information Service \\ U. S. Department of Commerce \\ 5285 Port Royal Road \\ Springfield, Virginia 22151
}

\title{
NOTE
}

This document is an interim memorandum prepared primarily for internal reference and does not represent a final expression of the opinion of Westinghouse. When this memorandum is distributed externally, it is with the express understanding that Westinghouse makes no representation as to completeness, accuracy, or usability of information contained therein. 


\section{NOTICE}

This report was prepared as an account of work sponsored by the United States Government. Neither the United States, nor the United States Atomic Energy Commission, nor any of their employees, nor any of their contractors, subcontractors, or their employees, makes any warranty, express or implied, or assumes any legal liability or responsibility for the accuracy, completeness or usefulness of any information, apparatus, product or process disclosed, or represents that its use would not infringe privately owned rights. 
Figure No.

1

2

3

4

5

Applied stress versus creep rate for several different irradiation times, and for a temperature of $300^{\circ} \mathrm{C}$, and a neutron flux of $10^{13} \mathrm{n} / \mathrm{cm}^{2} / \mathrm{sec}$. The data points are from Gilbert and Mastel.(28)

Creep rate versus time for several different stresses taken from the results of Figure 1.

Plot of total strain versus time calculated from the results of Figure 2 .

Plot of applied stress versus creep rate for a zirconiumbase alloy irradiated a neutron flux of $2.56 \times 10^{13} \mathrm{n} / \mathrm{cm}^{2} /$ sec at a temperature of $258^{\circ} \mathrm{C}$ (the conditions of Ibrahim's (30) specimens)。

A plot the total strain versus irradiation time for Ibrahim's conditions showing comparison between Ibrahim's data $(30)$ and theory (solid curves). 



\section{ABSTRACT}

A model for primary creep of clad materials in an irradiation environment is developed subject to the following assumptions: Creep is due to the glide of edge dis locations which encounter irradiation produced depleted zones, as barriers to their motion. The rate controling step is the climb of the dislocations through the zones. Irradiation affects the creep rate in two opposing ways. The vacancy-rich depleted zones resulting from the irradiation serve as pinning sites for the dislocations thus slowing their glide through the crystal. On the other hand, the radiationproduced interstitials and vacancies cause faster dislocation climb than would be expected out-of-plle. During the early stages of irradiation before the damage due to depleted zones has saturated far more isolated interstitials are produced than isolated vacancies. Consequently, the flux of interstitials to dislocations is substantially greater than that of vacancies causing the dislocations to climb relatively fast. Contributing also to the rapid creep rate in the early stages is the reduced number of obstacles avallable to pin the dislocations. Once the damage has saturated, It is generally assumed that unassociated vacancies and interstitials are produced in equal numbers; thus, the bias for climb due to an excess of only one type of point defect is substantially reduced. A quantitative model based on the above assumptions has been developed and results obtalned for zirconium-base alloys. 


\title{
Irradiation Induced Primary Creep
}

\author{
C. C. Dollins \\ R. P. Tucker
}

\section{Introduction}

A question of major importance in the development of nuclear reactors is the stability of the fuel clad materlal, especially with regard to Irradiation induced creep. A number of theories have emphasized various aspects of this complex phenomenon in efforts to predict in-pile creep rates $(1-15)$. Following a proposal by Nichols $(7)$, a quantitative model (12) was developed for steady-state creep in which the climb and glide of edge dislocations through irradiation-produced depleted zones is taken to be rate controlling. This steady-state model is applicable only after the depleted zone density has reached saturation. The present paper expands the previously developed model to treat primary creep, i.e., the transient creep at relatively short times before the irradiation damage has saturated. The basic model for the two cases is essentially the same, the differences being that for primary creep there are fewer depleted zones and the climb velocity is calculated in a somewhat different manner.

During neutron irradiation it is assumed under certain circumstances that the generation rates of single vacancles and interstitials are the same $(12,14,16-20)$. At higher irradiation temperatures such may indeed be the case. On the other hand, at lower temperatures and in materials where vacancy-rich depleted zones form and have a relatively long lifetime, the single vacancy and interstitial production rates are clearly not equal. The creep mechanism presented here is predicated on the existence of such vacancy-rich depleted zones.

A second consideration in developing the model relates to the role of biasing effects of sinks on radiation-produced point defects, e.g., the stronger affinity of dislocations for interstitials than for vacancies. During the early stages of irradiation prior to damage saturation it is proposed that such biasing effects play a relatively minor role in creep 
as these effects are overshadowed by the significantly greater number of interstitials compared to vacancies escaping the displacement spike.

The imbalance in production rates results in many more interstitials arriving at dislocations than vacancies and hence gives rise to irradiation enhanced dislocation climb. Under an applied stress the dislocations escape the defect array that pins them by climb and subsequently glide until pinned again. In this paper, as in the previously proposed model (12), the only obstacles to dislocation motion considered are the irradiation-produced depleted zones. The model itself is general for cases where depleted zones control creep. However, in this paper it is specifically applied to zirconium-base alloys, and the creep rates predicted by the model are compared to experimentally determined values.

Theory

\section{Depleted Zone Density}

In a crystalline solid bombarded by high energy neutrons ( $\mathrm{E}>\mathrm{IMeV}$ ), atoms can recelve sufficient energy to be dislodged from their lattice sites. These displaced atoms, i.e., the primary knock-on atoms subsequently lose energy through collisions with other lattice atoms. Toward the end of their trajectory they collide with many atoms in a localized region creating a vacancy-rich zone surrounded by interstitials at some distance away in the lattice. If it is assumed that each primary knock-on atom forms one depleted zone, then for a fast neutron flux, $\varphi$ (neutrons $/ \mathrm{cm}^{2} / \mathrm{sec}$ ) the zones are generated at the rate ${ }^{(21)}$

$$
F=\varphi \Sigma N_{0}
$$

where $\Sigma$ is the fast neutron scattering cross section of the matrix atoms and $\mathrm{N}_{0}$ is the number of lattice atoms per $\mathrm{cm}^{3}$. In this paper, the depleted zones are treated as if they were spherical voids of radius $r$.

A key factor in determining the creep rate is $N(r, t)$, the density of depleted zones as a function of time, $t$ and radius, $r$. The net change in depleted zone radius with time is proportional to the difference in the number of interstitials arriving and vacancies leaving the zone per unit time. The expression, previously developed, for the change of zone radius with time is (2l) 


$$
\frac{d r}{d t}=-\frac{D_{I} C_{I}}{r}-\frac{6 \Omega D_{V}}{b^{4}}\left[\exp \left(-E_{b} / k T\right)-C_{V}\right] \text {, }
$$

where $r$ is the zone radius; $D_{I}$ and $D_{V}$, the interstitial and vacancy diffusion coefficients, respectively; $C_{I}$ and $C_{V}$, the interstitial and vacancy concentrations, respectively; $E_{b}$, the vacancy binding energy to the zone; $b$, the Burger's vector; $\Omega$, the atomic volume; $6 \mathrm{D}_{\mathrm{V}} / \mathrm{b}^{2}$, the jump frequency and $k$ and $T$ have their usual meanings. The energy with which $a$ vacancy is bound to a zone is given by $(22)$

$$
E_{b}=E_{F}-\frac{2 \gamma \Omega}{r}
$$

where $\gamma$ is the surface tension and $E_{F}$ is the vacancy formation energy.

In order to use Eq. (2) to calculate the zone density, $N(r, t)$, it is necessary to calculate $\mathrm{C}_{\mathrm{I}}$ and $\mathrm{C}_{\mathrm{V}}$. Upon neutron bombardment interstitials are assumed to be produced at the rate $(21)$

$$
P_{I}=\eta \varphi \Sigma
$$

and single vacancies at the lesser rate

$$
\mathrm{P}_{\mathrm{V}}=\zeta \varphi \Sigma,
$$

where $\eta$ and $\xi$ are the number of interstitials and vacancies, respectively, that escape the depleted zone. These numbers are related by the expression

$$
\eta=\xi+\frac{4}{3} \frac{\pi r_{0}^{3}}{\Omega}
$$

where $r_{0}$ is the initial zone radius. The values of $\eta$ and $\xi$ are not wellknown. However, for the zirconium-base alloys discussed here, best results were obtained when values of 90 and 0.5 , respectively, were used. These values are in qualitative agreement with observed values in other systems (23). Under these assumptions, Eq. (6) ylelds that the initial depleted zone radius is about $8 \AA$ as before ${ }^{(21)}$. by (2l)

The interstitial concentration change with respect to time is given

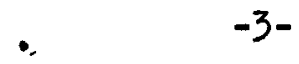




$$
\begin{aligned}
\frac{\mathrm{dC}_{I}}{\mathrm{dt}}=\pi \varphi \Sigma-\frac{2 \pi \rho \mathrm{D}_{I} \mathrm{C}_{I}}{\ln \left(\mathrm{r}_{I} / \mathrm{b}\right)} & -\int_{0}^{\mathrm{r}_{0}} 4 \pi r \mathrm{~N}(\mathrm{r}, \mathrm{t}) \mathrm{D}_{I} \mathrm{C}_{I} \mathrm{dr} \\
& -\frac{504\left(\mathrm{D}_{I}+\mathrm{D}_{V}\right)}{\mathrm{b}^{2}} \mathrm{C}_{I} \mathrm{C}_{V},
\end{aligned}
$$

where the first term on the right is the interstitial production rate; the second term, the loss rate to dislocations; the third, the loss rate to depleted zones; and the fourth, the loss rate to vacancles through recombination. In Eq. (7), $p$ is the dislocation density and $r_{1}$ is the average separation distance between dislocations.

The vacancy behavior is given by ${ }^{(21)}$

$$
\frac{d C_{V}}{d t}=\xi \varphi \Sigma-\frac{2 \pi \rho D_{V}\left(C_{V}-C_{0}\right)}{\ln \left(r_{I} / b\right)}+\int_{0}^{r_{0}} \frac{4 \pi r^{2}}{b^{2}} \frac{N(r, t)}{N_{0}} \frac{6 D_{V}}{b^{2}}\left[\exp \left(-E_{b} / k T\right)-C_{V}\right] d r
$$

$$
-504 \frac{\left(D_{I}+D_{V}\right)}{b^{2}} C_{I} C_{V}
$$

where $\mathrm{C}_{0}$ is the equilibrium thermal vacancy concentration. A computer program has been developed to solve simultaneousiy Eqs. (2), (7) and (8) for the interstitial and vacancy concentrations as well as the depleted zone density and size distribution as function of time. Point Defect Ceneration and Saturation

In the previous analysis $(12)$ of steady-state creep the depleted-zone density was constant and the assumption was made, as is often done, that vacancies and interstitials are generated in equal numbers $(16-20)$. Thus, if there were no biasing effects, the point defects would go to dislocations in equal numbers and no net climb would occur. However, since the strain field of a dislocation attracts interstitials more strongly than vacancies it was assumed that an excess of interstitials arrive at the dislocation resulting in a net climb. In the case of primary creep, this small 
preference of dislocations for interstitials over vacancies can be safely ignored because of the much greater number of interstitials than single vacancles. An exception to this interstitial predominance occurs if the irradiation temperature is so high that the depleted zones completely boil off their vacancies before $t$ single interstitial reaches them. Then, obviously, vacancies and interstitials are produced in equal numbers. On the other hand, if the temperature is sufficiently low, then the vacancies do not boil off from the depleted zones before some interstitials arrive; and thus, interstitials are produced in greater number than single vacancies. Up to some temperature near where point defects are produced in equal numbers, the interstitials because of their higher generation rate govern irradiation enhanced creep. The dividing line between these two temperature regimes for Type 304 stainless steel has been estimated by Harkness and $\mathrm{Li}^{\text {(19) }}$ to be $\sim 350^{\circ} \mathrm{C}$. The corresponding homologous temperature for zirconium-base alloys is estimated to be not less than $400^{\circ} \mathrm{C}$. Consequently, in the temperature range of interest $\left(\mathrm{T}<400^{\circ} \mathrm{C}\right.$ ) it is safe to assume that the point defects are not produced in equal numbers.

Because of the disparity in the generation of interstitials and single vacancies the concept of depleted zone damage saturation becomes very complex and deserves further consideration. For simplicity, ignore the relatively minor effect of isolated vacancy production entirely. Then at low temperatures recombination can also be ignored. Now assume that the point defects are at their steady-state concentrations with the defect structure of the material ${ }^{*}$, i.e., $\mathrm{dC}_{\mathrm{V}} / \mathrm{dt}=0$ and $\mathrm{dC}_{\mathrm{I}} / \mathrm{dt}=0$, then $\mathrm{Eq}$. (7) can be written

$$
\eta \varphi \Sigma=\frac{2 \pi \rho \mathrm{D}_{I} \mathrm{C}_{I}}{\ln \left(\mathrm{r}_{I} / \mathrm{b}\right)}+4 \pi<\mathrm{r}>\mathrm{N} \mathrm{D}_{\mathrm{I}} \mathrm{C}_{\mathrm{I}} \text {, }
$$

\footnotetext{
*The point defects are in steady-state with respect to the depleted zones. This does not mean that the depleted zone density is saturated or that the point defect concentrations will not change if the zone density changes.
} 
where for simplicity $<\mathrm{r}>$ is the average depleted zone radius and $N$ is the depleted zone density. Under the above assumptions, $\eta \varphi \Sigma$ is not only the interstitial production rate but also the vacancy production rate, where actually the vacancies are clustered and immobile in the form of depleted zones.

Interstitial migration to the vacancy clusters heals them, but during migration some interstitials are lost to other sinks, namely dislocations. Therefore, a mismatch is created between vacancies in clusters and the interstitials available to heal them. The production rate of these uncompensated vacancies, $V$, is given by the product of the number of interstitials produced and the fraction of the interstitials going to dislocations or sinks other than the vacancy clusters:

$$
V=\pi \varphi \Sigma\left(\frac{2 \pi \rho D_{I} C_{I} / \ln \left(r_{I} / b\right)}{\pi \varphi \Sigma}\right) .
$$

Solving Eq. (9) for $\mathrm{C}_{I}$ gives

$$
C_{I}=\frac{\pi \phi \Sigma}{2 \pi D_{I}\left(\frac{p}{\ln \left(r_{I} / b\right)}+2<r>N \mid\right.} \text {. }
$$

Substituting $\mathrm{C}_{I}$ from Eq. (11) into Eq. (10) gives

$$
V=\eta \varphi \Sigma\left(\frac{\rho}{\rho+2<r>N \ln \left(r_{1} / b\right)}\right)
$$

as the uncompensated vacancy production rate. Initially $\mathrm{N} \sim 0$ so that all vacancies in clusters are uncompensated, i.e., all interstitials go to dislocations. At much longer times, however, the term $2<r>{ }_{N} \ell_{n}\left(r_{I} / b\right)$ dominates $p$, the dislocation density. For example, if $\langle r>=5 \AA$, $\rho=10^{10} \mathrm{~cm}^{-2}$ and $\mathrm{N}=10^{19} \mathrm{~cm}^{-3}$, then $2<\mathrm{r}>\mathrm{N} \ln \left(\mathrm{r}_{1} / \mathrm{b}\right)$ is $\sim 500$ times larger than $\rho$. In this case the net uncompensated vacancy production rate, which is also the net damage production rate since all vacancies produced are in zones, is $0.2 \%$ of its initial value, i.e., for all practical purposes the damage has "saturated" and yet far more isolated interst1tials 
are being produced than vacancles.

The assumption that no vacancies escape the depleted zones is an extreme case indeed. Nevertheless, even if the majority of vacancies escape before any interstitials arrive at the zones the situation remains that more interstitials are being produced than single vacancies. In the strictest sense of the word, when the net damage (depleted zone) production rate is $0.2 \%$ of what 1 t was initially the zone density has not yet saturated, but by this point, the bias presented by the attraction of interstitials by dislocations is the dominant source of a mismetch in fluxes arriving at dislocations and from that point on seturation can be assumed. We treat here only the primary creep range before this effective saturation occurs. Dislocation Climb Velocity

The dislocation climb velocity depends on the point defect concentrations in the matrix and on the dislocation configurational arrangement, which usually is not well-known. In general, at low temperatures the interstitials play the predominant role; and at high temperatures, the vacancies, resulting in two regimes dependent on temperature. As mentioned already, the vacancy and interstitial concentrations are obtained by simultaneous solution of Eqs. (2), (7) and (8). Knowing these concentrations, the rate at which defects reach the dislocations can be determined. The rate of interstitial arrival at a dislocation per unit length is given by $2 \pi D_{I} C_{I} N_{0} / l_{0}\left(r_{I} / b\right)$ and the rate for vacancies is given by $2 \pi D_{V}\left(C_{V}-C_{0}\right) N_{0} / \ln \left(r_{1} / b\right)$. Thus, the net number of interstitials reaching the dislocation is the difference,

$$
\frac{2 \pi}{\ln \left(r_{I} / b\right)}\left(D_{I} C_{I}-D_{V} C_{V}+D_{V} C_{O}\right) N_{O}
$$

The dislocation climb velocity due to the mismatch in defect fluxes is

$$
v_{c}^{\prime}=\frac{2 \pi}{\ln \left(r_{I} b\right)}\left(D_{I} C_{I}-D_{V} C_{V}+D_{V} C_{0}\right) N_{0}^{1 / 3}
$$

At high temperatures, thermal vacancies greatly depress the interstitial concentration. The climb velocity is then determined by vacancy behavior as proposed by Weertman (24). According to Weertman the applied stress results in differences in the equilibrium concentration of vacancies at 
dislocations with different orientations so that a net flow of vacancies from dislocations of one orientation to those of another orientation occurs resulting in climb of both sets of dislocations. The climb velocity is then given by $(12)$

$$
v_{c}^{\prime \prime}=\frac{2 \pi D_{v} c_{0}\left[\exp \left(\sqrt{3} \sigma b^{3} / k T\right)-1\right]}{N_{0}^{2 / 3} \ln (1 / b \sqrt{\pi \rho})},
$$

where we assume that $\sigma$ is the effective shear stress at the dislocation. It is assumed that the generalized applied stress ${ }^{(25)}, \sigma_{\theta}$, equals the shear stress at the dislocation, $\sigma$, times $\sqrt{3}$, plus an internal stress, $\sigma_{I}{ }^{(26)}: \sigma_{a}=\sqrt{3} \pi+\sigma_{I}$.

For the assumed dislocation geometry described previously ${ }^{(12)}$, the average climb velocity can be expressed as

$$
v_{c}=1 / 2\left|v_{c}^{\prime}-v_{c}^{\prime \prime}\right|+1 / 2\left|v_{c}^{\prime}+v_{c}^{\prime \prime}\right|
$$

Over much of the temperature range, it is, in fact, the depleted zones that govern the vacancy and interstitial concentrations and thus the climb velocity. However, at relatively high temperatures where the zones dissolve quickly after formation and the thermal vacancy concentration is high the depleted zones no longer control the climb velocity. Instead it is the vacancy concentration itself that controls.

\section{Creep Model}

In the creep model, which is basically the same as that proposed previously(12), the depleted zones serve as barriers to dislocations which are in the form of loops and have been emitted from Frank-Read sources. The edge segments are assumed to be rate controlling and may escape the zones at which they are pinned in various ways. The three mechanisms which contribute to the unpinning process are (1) dislocation climb out of the zone, (2) thermally activated cutting of the zone, and (3) zone dissolution. The remainder of this section briefly outlines the creep model; for further details the reader is referred to Reference 12.

At $0^{\circ} \mathrm{K}$ under an applied stress $\sigma$, the distance, $h$, a dislocation must climb in order to escape the depleted zones pinning it is 


$$
h=r+\frac{A}{l^{\prime}} \sqrt{1-\frac{\sigma}{\sigma_{\max }}}
$$

where $\sigma_{\max }$ is the maximum shear stress a dislocation can sustain and remain pinned, $r$ is the zone radius, $l^{\prime}$ is the distance between defects along the dislocation line, and $A$ is the area swept out by the bowed dislocation. The general expression for $A$ when the dislocation bows both from applied stress and climb is

$$
A=\frac{\pi R^{2}}{2}-\sqrt{R^{2}-\frac{l^{\prime 2}}{4}} \frac{l^{\prime}}{2}-R^{2} \sin ^{-1} \frac{\sqrt{R^{2}-\left(l^{\prime 2} / 4\right)}}{R},
$$

where

$$
\mathrm{R}=\frac{\mu \mathrm{b}}{4 \pi(1-\nu) \sigma_{\max }} \ln \frac{\mathrm{l}^{\prime}}{\mathrm{b}}
$$

( $\omega=$ shear modulus, $\nu=$ Poisson's ratio). Following Frledel ${ }^{(27)}$, the effective distance between pinning points along the dislocation just prior to breakaway is given by

$$
l^{\prime}=\left(\frac{\omega b}{\sigma_{\max }^{2} \times N}\right)^{1 / 3}
$$

where $r$ is the average zone radius and $N$ is the depleted zone density per unit volume. Here $\sigma_{\max }$ is used because breakaway does not occur until the dislocation has climbed and bowed to such an extent that its radius is very nearly that of an unclimbed dislocation acted upon by the maximum stress it can withstand. For an edge dislocation restrained by spherical voids (depleted zones) the maximum stress at $0^{\circ} \mathrm{K}$ is $(12)$

$$
\sigma_{\max }=\left[\frac{\mu b}{2 \pi(1-\nu)}\left(\frac{\pi^{2}}{12}+\ln \frac{r}{b}\right)+0.2 \mu b\right]^{3 / 2}\left(\frac{2 r N}{\omega b}\right)^{1 / 2} .
$$

The total time, $T$, that a dislocation is pinned depends on the frequency, $v^{\prime}$, with which it attempts to overcome the barriers as well as on the stress and time dependent energy profile, $u(\sigma, t)$, characterizing the barrier. The stress applied to the dislocation assists it in its escape 
from the energy well as does the dislocation climb. Details regarding the assumed $u(\sigma, t)$ are given in Reference 12 . The total transit time of the dislocation between two pinning points, $T$, is given by the solution of the integral

$$
\int_{0}^{T} v^{\prime} \exp \left(-\frac{u(\sigma, t)}{k T}\right) d t=1
$$

Once $\tau$ is known, the average dislocation glide velocity can be calculated,

$$
\mathrm{v}=1 /\left(2 \times \mathrm{N} \ell^{\prime} \tau\right)
$$

and furthermore the creep rate can be determined using the expression (12)

$$
i=\frac{2 \pi^{2} M L^{2}(1-v) \& \sigma}{\mu},
$$

where $M$ is the number of Frank-Read sources per $\mathrm{cm}^{3}$ and $L$ is the total glide length of a dislocation and is taken to be the radius of the subgrains. Results and Discussion

In the model developed above a basic assumption is that the depleted zones are entirely responsible for the hardening. Consequently, at very early times and for applied stresses in excess of the internal stress, $\sigma_{I}$, the creep rate is very rapid; in fact, initially it is infinite. This behavior, of course, is unrealistic and hence the model fails at very short times when the depleted zone density is too low to be rate controlling. In addition, at present, means for calculating the transient behavior of the dislocation density, internal stress, Frank-Read source density, and cell size are not well established, and thus they are held constant with time. However, it is assumed that the dislocation density, etc., will stabilize before the depleted zones become rate controlling, and hence this transient behavior is somewhat of less concern than the problem associated with the assumption that depleted zones are rate controlling at early times. Even these shortcomings, as serious as they may be for very early transient behavior, fail to obscure the major characteristics of most of the range of primary creep; for the model is able to predict creep in agreement with experimentally determined values for the zirconium-base alloys examined. 
In this paper, results predicted by the model are shown for two sets of irradiation conditions, namely: (1) Flux $=10^{13}$ neutrons $/ \mathrm{cm}^{2} \cdot \sec \cdot(\mathrm{E}>1 \mathrm{MeV})$; Irradiation Temperature $=300^{\circ} \mathrm{C}$ and (2) Flux $=2.56 \times 10^{13} \mathrm{n} / \mathrm{cm}^{2} \cdot \mathrm{sec}$ $(E>I \mathrm{MeV})$; Irradiation Temperature $=258^{\circ} \mathrm{C}$. The threshold stress in the model below which dislocations cannot move between barriers is assumed to be $0.6 \times 10^{9}$ dynes $/ \mathrm{cm}^{2}$. Figure $I$ is a plot of applied generalized stress versus strain rate at several different times for the first set of irradiation conditions. As a function of time the creep rate at all stresses decreases and the stress at which rapid yielding occurs increases as a result of increased irradiation damage. In the intermediate stress region, where often it is said that the strain rate obeys a power law dependence on stress, i.e., $:=\mathrm{A} \sigma^{\mathrm{n}}$, it is interesting to note that the $\mathrm{n}$ values predicted from Figure 1 decrease with fluence or time of Irradiation. This decreased dependence on stress suggests that with increasing irradiation the depleted zones become so numerous that the applied stress alcne is less ible to cvercome the barriers. Also plotted in Figure 1 are the experimental data of Gilbert and Mastel (28) for steady-state creep of $\mathrm{Zr}-2.5 \mathrm{wt} . \% \mathrm{Nb}$ at $300^{\circ} \mathrm{C}$ and a flux of $\sim 9 \times 10^{12}$ neutrons $/ \mathrm{cm}^{2} / \mathrm{sec}(\mathrm{E}>1 \mathrm{MeV})$. There is fair agreement between the steady-state creep curve obtained theoretically and these data. The values used to calculate the curves are given in Table $I$.

The curves in Figure 1 are cross-plotted as strain rate versus time for several different stresses in Figure 2. The curves in Figure 2 point out quite clearly that the strain rate decreases rapialy with time from very high initial value, where the depleted zone density is too low to be rate controlling. Thus, at present, the very short time creep rates must be adjusted in accord with experimental measurements. For the zirconium-base alloys considered here the creep data of Ibrahim $(30)$ were used as a guide for the Initial creep rate at comparable stresses. Graphical integration (see Table II) of the curves in Figure 2 ylelds the total strain as a function of time and is shown in Figure 3 for several applied stresses for the first set of irradiation conditions.

In order to test the model more exactly with experimental data, curves similar to those in Figures $1-3$ were generated for the irradiation conditions used by Ibrahim $(30)$, namely, $258^{\circ} \mathrm{C}$ and a flux of 2.56 neutrons $/ \mathrm{cm}^{2}$. sec. Figure 4 is a plot of the creep rate versus applied stress under these 
Irradiation conditions. The curves show characteristics similar to the curves in Figure 1. However, the higher flux and lower temperature generally raise the stress at which rapid yielding occurs. Furthermore, steady-state is reached at a higher fluence, and for a given stress and fluence the creep rate is slightly reduced compared to the corresponding curves in Figure 1. A cross plot of the curves in Figure 4 as strain rate versus time for several stresses (not shown) was graphically integrated (see Table III) to give the total strain versus time curves shown in Figure 5. The data points are those of Torahim and reasonable agreement between theory and experiment is observed. The parameters in the model have been chosen to give agreement at steadystate with data for $\mathrm{Zr}-2.5 \mathrm{wt}$. \% $\mathrm{Nb}$ as shown in Figure 1 . Since at low stresses $\mathrm{Zircaloy}$ and $\mathrm{Zr}-\mathrm{Nb}$ alloys have simflar creep rates ${ }^{(28)}$ better agreement between the model and data for Zircaloy is expected in Figure 5 at the lower stresses.

\section{Conclusions}

1. A model for primary as well as steady-state creep in which irradiation produced depleted zones are the barrlers to dislocation motion is presented.

2. In the model the excess production rate of one type of point defect over the other is the driving force for primary creep.

3. At low temperatures, say below $\sim 400^{\circ} \mathrm{C}$ for $\mathrm{Zr}$-base alloys, the interstitial production rate is substantially greater than that of single vacancies.

4. The rapid creep rate in $\mathrm{Zr}$-base alloys at stresses above $0.6 \times 10^{9}$ dynes $/ \mathrm{cm}^{2}$ (9000 psi) during early times, i.e., primary creep results from the following:

(a) The ratio of interstitial to single vacancy production is largest during the early stages yielding high dislocation climb velocities.

(b) The number of radiation-produced obstacles to dislocation motion is least during the early stages of irradiation. Acknowledgments

The authors would like to thank F. A. Nichols. This work is part of the LWBR Development Program under Contract Number AT-(36-1)-GEN-14 of the U. S. Atomic Energy Commission. 
REFERENCES

1. G. Schoeck, "Influence of Irradiation on Creep", J.Appl. Phys. 29, 112 (1958).

2. D. Mosedale, "Influence of Irradiation on Creep", J. Appl. Phys 33, $3142-3143$ (1962).

3. A. C. Roberts and A. H. Cottrell, "Creep of Alpha Uranium During Irradiation with Neutrons", Ph1l. Mag. 1, 711-717 (1956).

4. R. V. Hesketh, "Application of the Generalized Theory of Ylelding Creep to Irradiation Creep in Zirconium Alloys", J. Nucl. Mater. 26, 77-86 (1968).

5. G. R. Piercy, "Mechanisms for the In-Reactor Creep of Zirconium Alloys", J. Nucl. Mater. 26, 18-50 (1968).

6. F. A. Nichols, "Theory of the Creep of Zircaloy During Neutron Irradiation", J. Nucl. Mater. 30, 249-270 (1969).

7. F. A. Nichols, "On the Mechanisms of Irradiation Creep in ZircontumBase Alloys", J. Nucl. Meter. 37, 59-70 (1970).

8. F. A. Nichols, "Reply to 'Mosedale's Note on Dislocation Climb and Irrsdiation"", J. Nucl. Meter. 35, 251-252 (1970).

9. D. Mosedale, "Dislocation Climb and Irradiation", J. Nucl. Mater. 35, 250 (1970).

10. R. V. Hesketh, "Diffusion Creep Under Neutron Irradiation", J. Nucl. Mater. 29, 217-222 (1969).

11. G. W. Lewthwaite, "The Acceleration of Climb-Controlled Creep by Neutron Irradiation", J. Nucl. Mater. 38, 118-120 (1971).

12. C. C. Dollins, "Irradiation Creep Associated with Dislocation Climb", Rad. Effects II, 123-131 (1971).

13. R. V. Hesketh, "Dislocation Climb: First Catch Your Poisson", J. Nucl. Mater. 35, 253 (1970).

14. W. J. Duffin and F. A. Nichols, "The Effect of Irradiation on Diffusion-Controlled Creep Processes", J. Nucl. Mater. 45, 302-316 (1972/73).

15. J. H. Gittus, "Theory of Dislocation-Creep Due to the Frenkel Defects or Interstitialcies Produced by Bombardment with Energetic Particles", Phil. Mag. 25, 345-354 (1972). 
16. J. L. Katz and H. Wiedersich, "Nucleation of Voids in Materials Supersaturated with Vacancies and Interstitials", J. of Chem. Phys. 55, 1414-1425 (1971).

17. H. Wiedersich, "On the Theory of Vold Formation During Irradiation", Rad. Effects 12, 111-125 (1972).

18. K. C. Russe11, "Nucleation of Volds in Irradiated Metals", Acta Met. 19, 753-758 (1971).

19. S. D. Harkness and Che-Yu L1, "A Study of Vold Formation in Fast Neutron-Irradiated Metals", Met. Trans. 2, 1457-1470 (1971).

20. R. Bullough and R. C. Perrin, "The Mechanism and Kinetics of Void Growth During Neutron Irradiation", in Irradiation Effects on Structural Alloys for Nuclear Reactor Applications, ASTM STP-484, American Soclety for Testing and Materials, 1970, pp 317-331.

21. C. C. Dollins, "Depleted Zone Formation and Recovery During Neutron Irradiation", Rad. Effects 11, 33-38 (1971).

22. C. C. Dollins, "Post-Irradiation Recovery of Irradiation Damage", Rad. Effects 16, 271-280 (1972).

23. T. H. Blewitt, A. C. Klank, T. Scott and W. Weber, "Experiments to Determine the Number of 'Free Vacancies' in a Fission Neutron Displacement Cascade", in Radiation-Induced Voids in Metals edited by J. W. Corbett and L. C. Ianniello (USAEC Office of Information Services, 1972) p 757-768.

24. J. Weertman, "Theory of Steady-State Creep Based on Dislocation Climb", J. App1. Phys. 26, 1213-1217 (1955).

25. G. E. Dieter, Jr., Mechanical Metullurgy (McGraw-H1ll Book Co., New York, 1961) p 62 .

26. A. Seeger, "The Mechanism of Glide and Work Hardening in Face-Centered Cubic and Hexagonal Close-Packed Metals", in Dislocations and Mechanical Properties of Crystals edited by J. C. Fisher, W. G. Johnston, R. Thomson and T. Vreeland (John Wiley and Sons, Inc., New York 1957) pp 243-329.

27. J. Friedel, "On the Elastic Limit of Crystals", in Electron Microscopy and Strength of Crystals, edited by G. Thomas and J. Washburn (Interscience Publishers, New York, 1963) p 605-649.

28. E. R. G1lbert and B. Mastel, "Stress Dependence of the In-Reactor Uniaxial Creep of $\mathrm{Zr}-2$ and Zr-2.5 Nb", Trans. Am. Nucl. Soc. 12, $132-133$ (1969). 
29. 0. M. Kanel and Y. A. Kraftmakher, "Vacancy Formation in Zirconium", Sov. Phys. Solid State $8,232-233$ (1966).

30. E. F. Tbrahim, "In-Reactor Creep of Zirconium-Alloy Tubes and Its Correlation with Uniaxial Data" in Applications-Related Phenomena in Zirconium and Its Alloys. A Symposium sponsored by the American Soclety for Testing and Materials, Philadelphia, Pa., 5-7 November 1968, pp 18-36, ASTM Special Technical Publication No. 458, American Society for Testing Materials, Philadelphia, Pennsylvania, 1969. 

Table I

$$
\begin{aligned}
& D_{V}=0.38 \exp (-28,000 / R T)^{(21)} \\
& D_{I}=7.5 \times 10^{-4} \exp (-7000 / R T)^{(21)} \\
& \mathrm{b}=3.23 \AA^{(27)} \\
& \mathrm{N}_{\mathrm{o}}=4.2 \times 10^{22} \text { atoms } / \mathrm{cm}^{3} \\
& \Sigma=4 \text { barns }(5) \\
& \mathrm{E}_{\mathrm{f}}=1.75 \mathrm{eV}^{(29)} \\
& E_{m}=1.2 \mathrm{ev}^{(5)} \\
& \eta=90 \\
& \xi=.5 \\
& Y=1000 \mathrm{ergs} / \mathrm{cm}^{2} \text { (assumed) } \\
& \psi=3.45 \times 10^{11}(27) \\
& \nu=.34^{(27)} \\
& C_{0}=\exp (4.6) \exp \left(-E_{f} / K T\right)^{(29)} \\
& \rho=3.5 \times 10^{11} \text { (assumed) } \\
& \sigma_{I}=9000 \mathrm{psi} \text { (assumed) } \\
& \nu^{\prime}=10^{13} \mathrm{~b} / \mathrm{l}^{\prime} \mathrm{sec}^{-1} \\
& L=2 \times 10^{5} / \sigma_{a}(12) \\
& M=1.25 \times 10^{5} \sigma_{a}(12)
\end{aligned}
$$




$$
\sigma=1 \times 10^{9} \text { dynes } / \mathrm{cm}^{2}
$$

$$
\begin{aligned}
& T=573^{\circ} \mathrm{C} \\
& \varphi=10^{23} \mathrm{n} / \mathrm{cm}^{2} / \mathrm{sec}
\end{aligned}
$$

\begin{tabular}{|c|c|c|c|c|c|}
\hline $\begin{array}{l}\text { Final } \\
\text { Time }\end{array}$ & $\begin{array}{c}\Delta \text { Time } \\
\mathrm{hr} \text {. }\end{array}$ & $\left(h r^{-1}\right)$ & $\begin{array}{l}\Delta \text { strain } \\
=\dot{\epsilon} \Delta t\end{array}$ & $\begin{array}{l}\text { Total } \\
\text { Strain }\end{array}$ & $\%$ \\
\hline $\begin{array}{l}1.39 \\
2.78 \\
5.56 \\
11.1 \\
27.8 \\
83.4 \\
222 \\
556 \\
1390 \\
2780\end{array}$ & $\begin{array}{c}1.39 \\
1.39 \\
2.78 \\
5.56 \\
16.7 \\
55.6 \\
139 \\
334 \\
834 \\
1390\end{array}$ & $\begin{array}{l}2 \times 10^{-4} \\
2 \times 10^{-5} \\
6.3 \times 10^{-6} \\
3.3 \times 10^{-6} \\
1.85 \times 10^{-6} \\
1.05 \times 10^{-6} \\
5.9 \times 10^{-7} \\
4.0 \times 10^{-7} \\
3.55 \times 10^{-7} \\
2.75 \times 10^{-7}\end{array}$ & $\begin{array}{l}2.78 \times 10^{-4} \\
2.78 \times 10^{-5} \\
1.75 \times 10^{-5} \\
1.84 \times 10^{-5} \\
3.09 \times 10-5 \\
5.84 \times 10-5 \\
8.2 \times 10-5 \\
1.34 \times 10^{-4} \\
2.96 \times 10-4 \\
3.82 \times 10^{-4}\end{array}$ & $\begin{array}{l}2.78 \times 10^{-4} \\
3.06 \times 10^{-4} \\
3.24 \times 10^{-4} \\
3.42 \times 10^{-4} \\
3.73 \times 10^{-4} \\
4.31 \times 10^{-4} \\
5.13 \times 10^{-4} \\
6.47 \times 10^{-4} \\
9.43 \times 10^{-4} \\
1.33 \times 10^{-3}\end{array}$ & $\begin{array}{l}.0278 \\
.0306 \\
.0324 \\
.0342 \\
.0373 \\
.0431 \\
.0513 \\
.0647 \\
.0943 \\
.133\end{array}$ \\
\hline \multicolumn{6}{|c|}{$\sigma=1.5 \times 10^{9}$ dynes $/ \mathrm{cm}^{2}$} \\
\hline $\begin{array}{l}11.1 \\
27.8 \\
83.4 \\
222 \\
556 \\
1390 \\
2780\end{array}$ & $\begin{array}{l}11.1 \\
16.7 \\
55.6 \\
139 \\
334 \\
834 \\
1390\end{array}$ & $\begin{array}{r}2 \times 10^{-4} \\
5 \times 10^{-5} \\
1.85 \times 10^{-6} \\
9 \times 10^{-7} \\
6 \times 10^{-7} \\
4.7 \times 10^{-7} \\
4.0 \times 10^{-7}\end{array}$ & $\begin{array}{l}2.22 \times 10^{-3} \\
8.35 \times 10^{-4} \\
1.03 \times 10^{-4} \\
1.25 \times 10^{-4} \\
2 \times 10^{-4} \\
3.9 \times 10^{-4} \\
5.56 \times 10^{-4}\end{array}$ & $\begin{array}{l}2.22 \times 10^{-3} \\
3.06 \times 10^{-3} \\
3.16 \times 10^{-3} \\
3.29 \times 10^{-3} \\
3.49 \times 10^{-3} \\
3.88 \times 10^{-3} \\
4.44 \times 10^{-3}\end{array}$ & $\begin{array}{l}.222 \\
.306 \\
.316 \\
.329 \\
.349 \\
.388 \\
.444\end{array}$ \\
\hline \multicolumn{6}{|c|}{$\sigma=2 \times 10^{9}$ dynes $/ \mathrm{cm}^{2}$} \\
\hline $\begin{array}{l}27.8 \\
83.4 \\
222 \\
556 \\
1390 \\
2780\end{array}$ & $\begin{array}{l}27.8 \\
55.6 \\
139 \\
334 \\
834 \\
1390\end{array}$ & $\begin{array}{l}2 \times 10^{-4} \\
5.7 \times 10^{-6} \\
1.12 \times 10^{-6} \\
7.2 \times 10^{-7} \\
5.5 \times 10^{-7} \\
4.8 \times 10^{-7}\end{array}$ & $\begin{array}{l}5.55 \times 10^{-3} \\
3.17 \times 10^{-4} \\
1.555 \times 10^{-4} \\
2.4 \times 10^{-4} \\
4.6 \times 10^{-4} \\
6.7 \times 10^{-4}\end{array}$ & $\begin{array}{l}5.55 \times 10^{-3} \\
5.87 \times 10^{-3} \\
6.03 \times 10^{-3} \\
6.27 \times 10^{-3} \\
6.73 \times 10^{-3} \\
7.40 \times 10^{-3}\end{array}$ & $\begin{array}{l}.555 \\
.587 \\
.603 \\
.627 \\
.673 \\
.740\end{array}$ \\
\hline
\end{tabular}


TABLE III

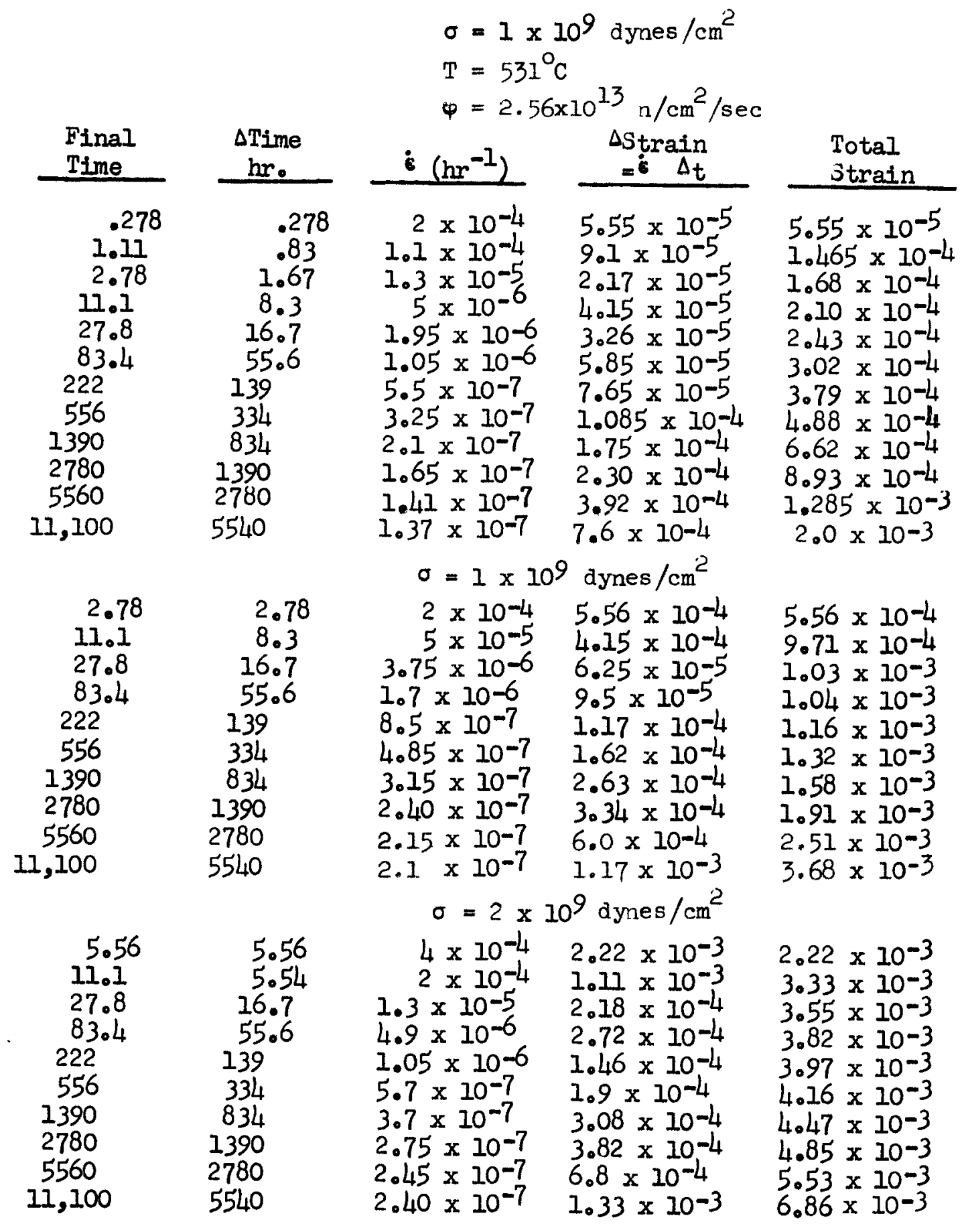

WU.S. GOVERNMENT PRINTING OFFICE: 1974-705-653/251 


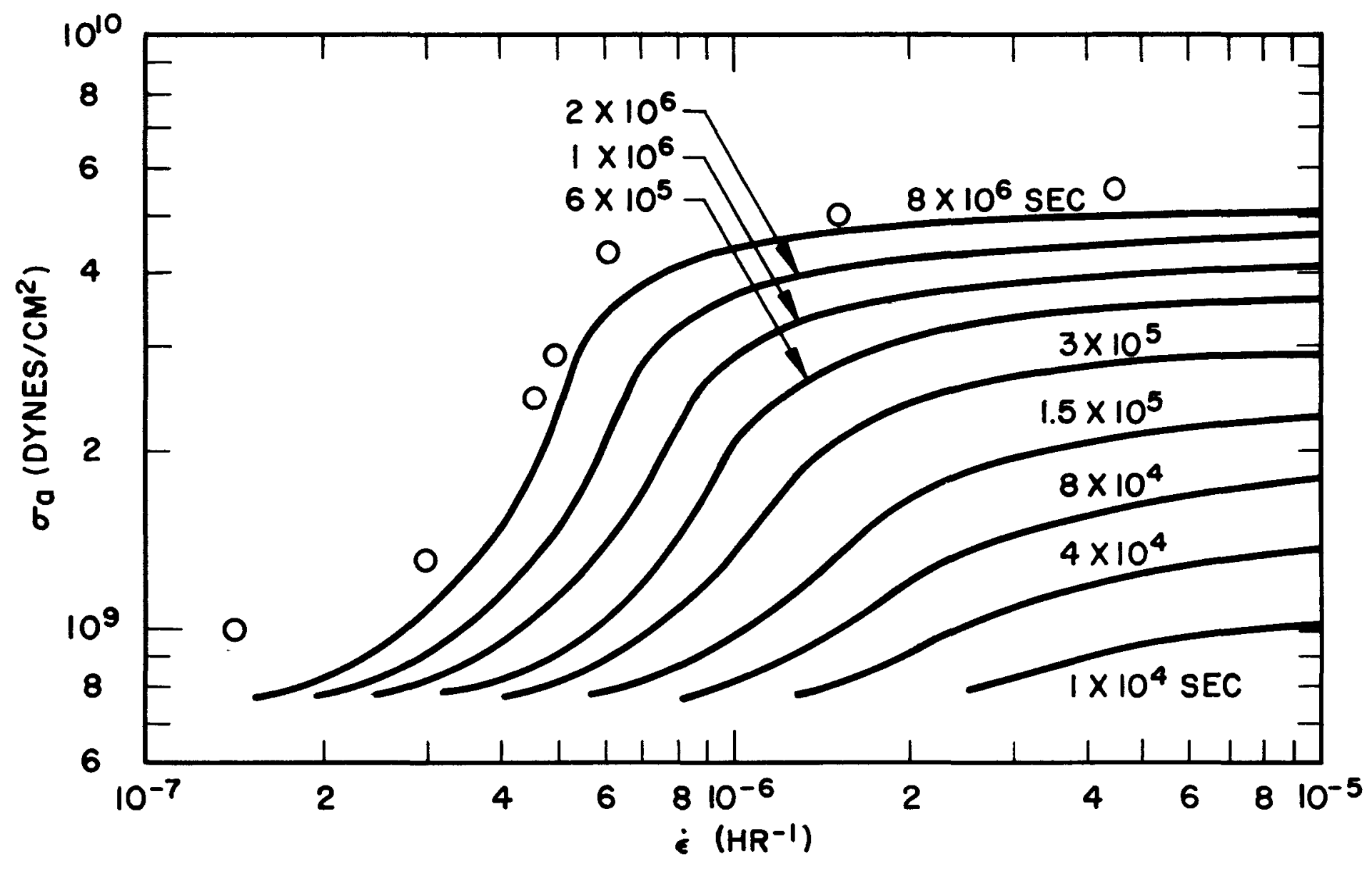

FIGURE 1 


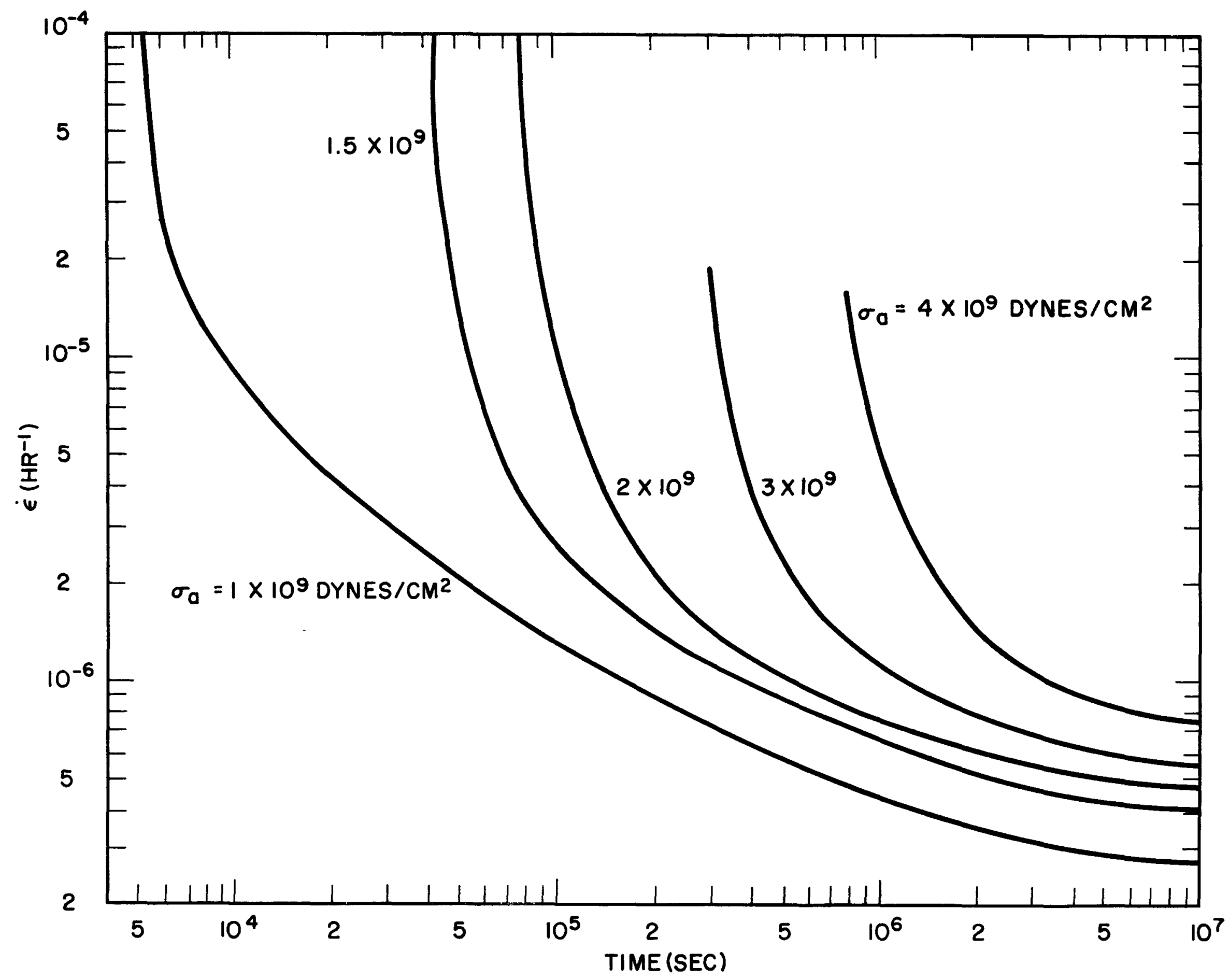




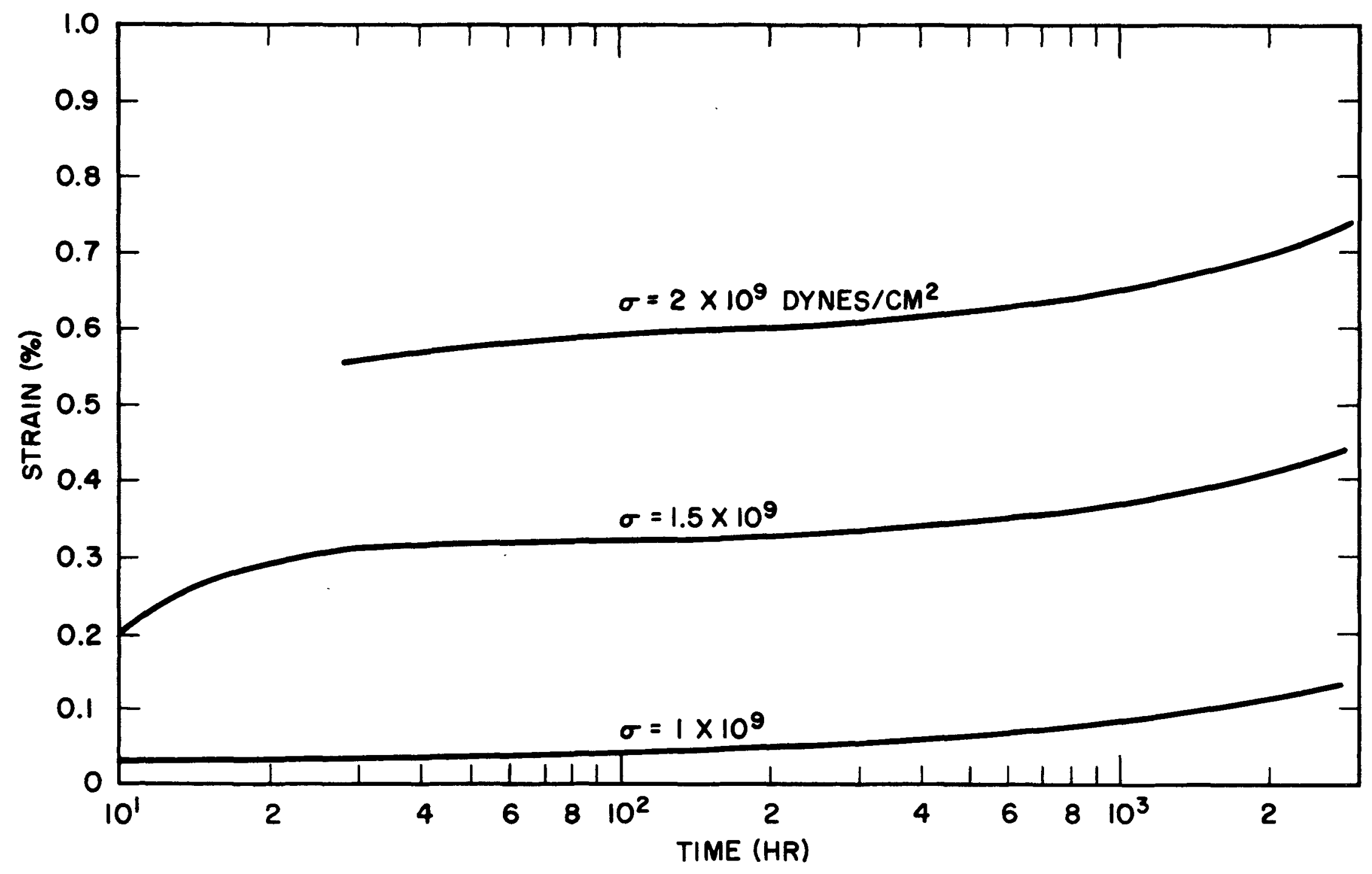

FIGURE 3 


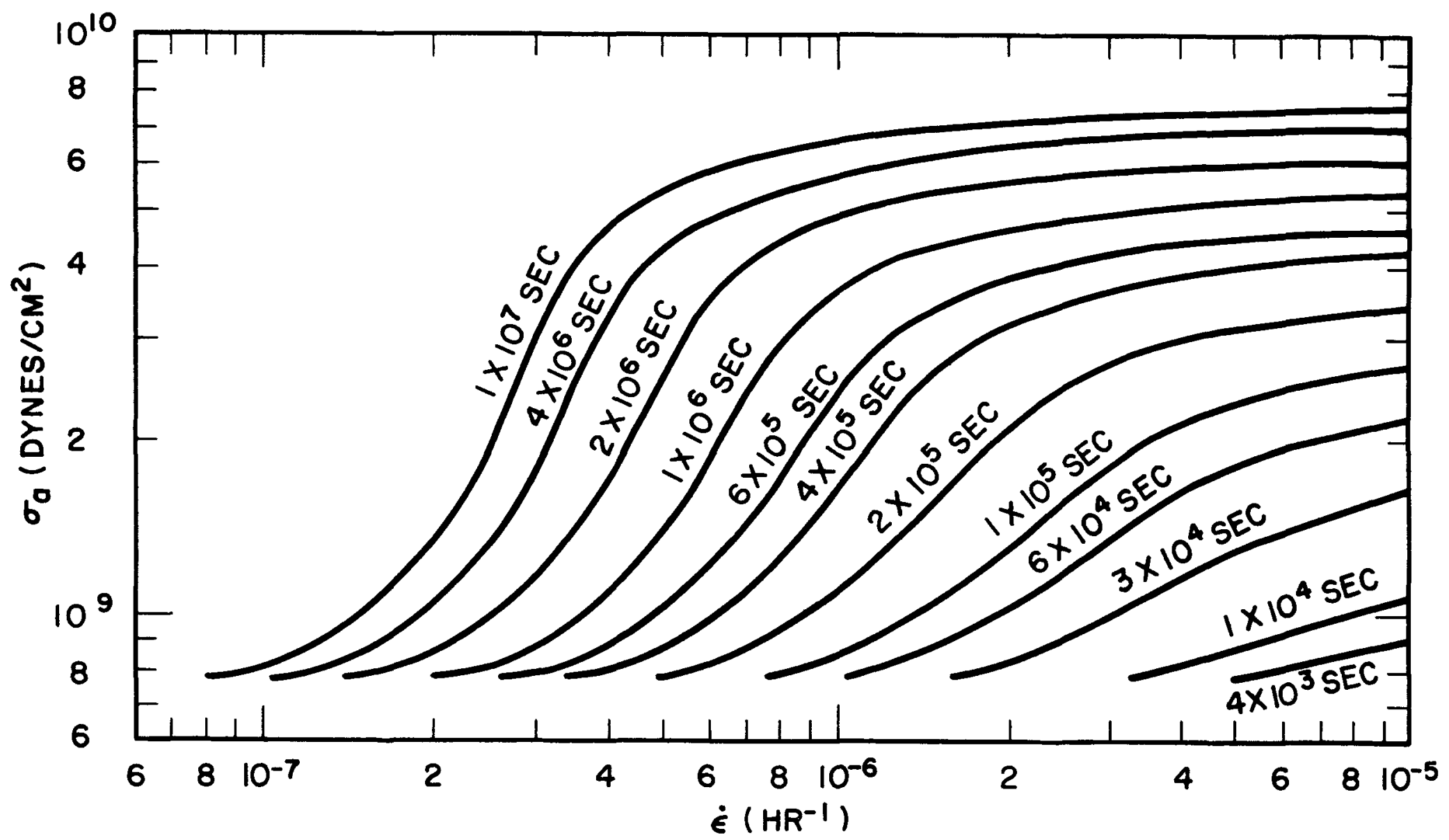

FIGURE 4 


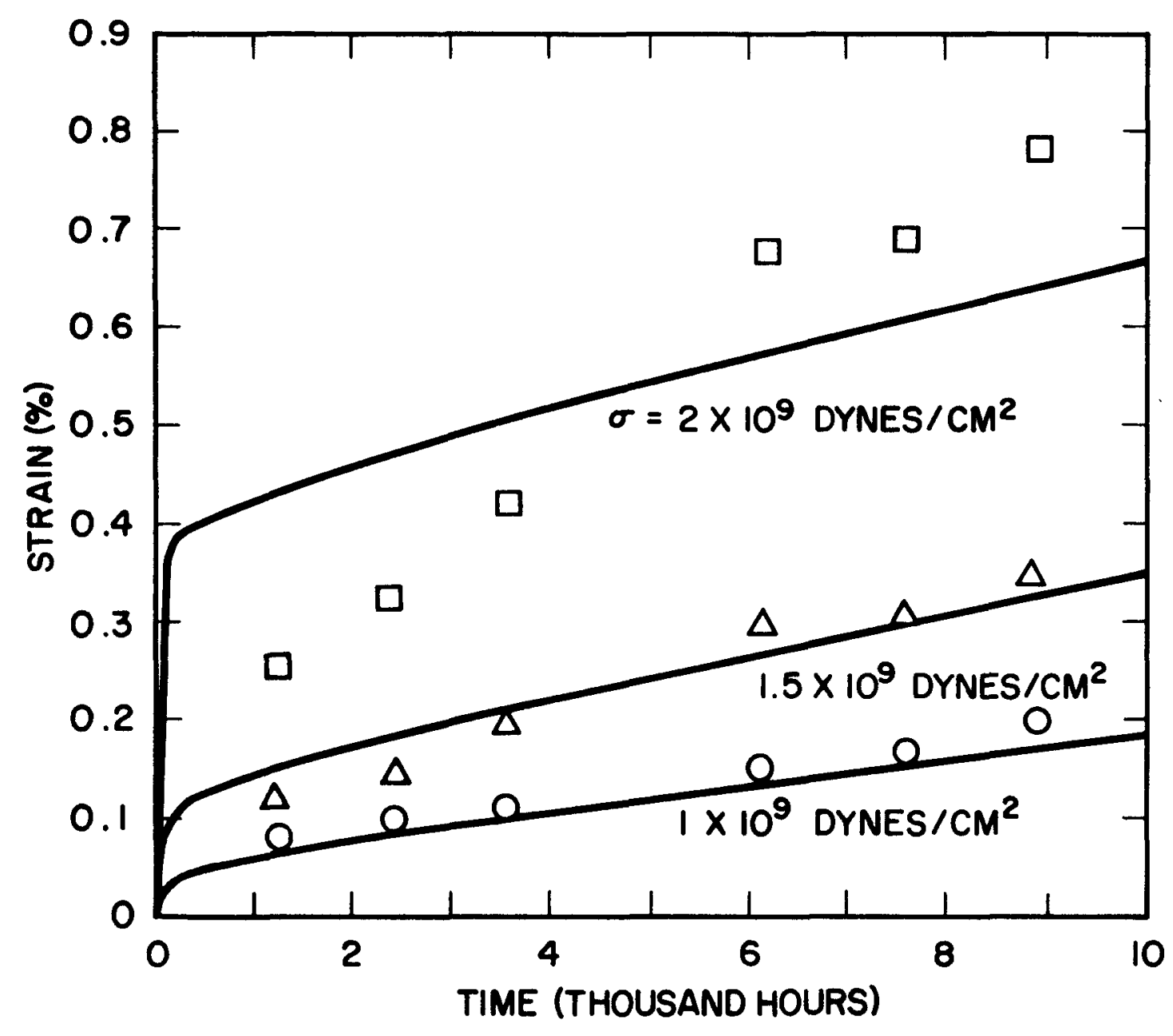

FIGURE 5 